\title{
Hydrogen-Location-Sensitive Modulation of the Redox Reactivity for Oxygen-deficient $\mathrm{TiO}_{2}$
}

Yao Guo ${ }^{\dagger \ddagger}$, Shunwei Chen ${ }^{\dagger}$, Yaoguang Yu*†, Haoran Tian ${ }^{\dagger}$, Yanling Zhao ${ }^{\dagger \neq}$, Ji-Chang Ren',

Chao Huang ${ }^{\dagger}$, Haidong Bian ${ }^{\#}$, Miaoyan Huang ${ }^{\dagger}$, Liang An ${ }^{\perp}$, Yangyang Li $^{\#}$, Ruiqin Zhang*广§

Department of Physics, City University of Hong Kong, Hong Kong SAR, P. R. China

*Shenzhen Research Institute, City University of Hong Kong, Shenzhen, P. R. China

'Nano and Heterogeneous Materials Center, School of Materials Science and Engineering, Nanjing University of

Science and Technology, Nanjing, Jiangsu, P. R. China

\#Department of Materials Science and Engineering, City University of Hong Kong, Hong Kong SAR, P. R. China

${ }^{\perp}$ Department of Mechanical Engineering, The Hong Kong Polytechnic University, Hong Kong SAR, P. R. China

§Beijing Computational Science Research Center, Beijing, P. R. China 


\section{Table of Contents}

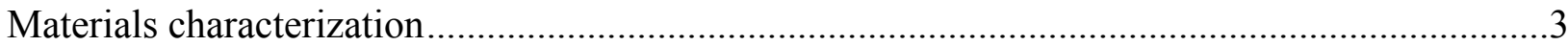

Photoelectrochemical and photocatalytic measurements .......................................................3

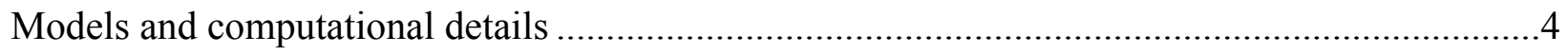

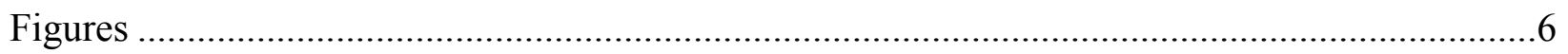

Section I Synthetic procedure and texture characterization .............................................. 14

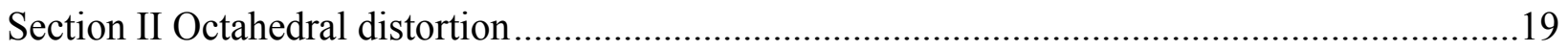

Section III Time-resolved photoluminescence spectrum ................................................22

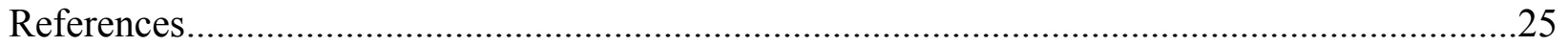




\section{Materials characterization}

The X-ray diffraction (XRD) patterns of samples were recorded using a Philips powder diffractometer with $\mathrm{Cu} K_{\alpha}$ radiation $(\lambda=1.54051 \AA)$. The Raman analysis was carried out on HORIBA/LabRAM HR Evolution Raman Microscope with $532 \mathrm{~nm}$ laser pulse for the excitation. The X-ray photoelectron spectroscopy (XPS) measurement was performed using the PHI5802 system with $\mathrm{Al} K_{\alpha}$ source $(1486.6 \mathrm{eV})$. The $\mathrm{C} 1 \mathrm{~s}$ peak $(284.6 \mathrm{eV})$ assigned to adventitious carbon was selected as the reference for the calibration of the binding energy. The UV-vis diffuse reflectance spectra were recorded by using a Shimadzu UV3600 spectrophotometer equipped with an integrating sphere, where $\mathrm{BaSO}_{4}$ was used as the reflectance standard. The reflectance was converted to absorbance via the standard Kubelka-Munk method. Electron paramagnetic resonance (EPR) measurement was carried on a JES- FA300 EPR spectrometry by applying an Xband $(9.06 \mathrm{GHz}, 1.0 \mathrm{~mW})$ microwave and sweeping magnetic field at $77 \mathrm{~K}$. Solid-state ${ }^{1} \mathrm{H}$ magicangle spinning (MAS) nuclear magnetic resonance (NMR) spectra were acquired on an VNMRS spectrometer manufactured by Agilent Systems operating at a field strength of 14 tesla $(600 \mathrm{MHz})$. Spectroscopy data were collected using VNMRJ Version-4.0. The hydrogenated samples for the solid-state ${ }^{1} \mathrm{H}$ NMR test were first annealed under vacuum at $220{ }^{\circ} \mathrm{C}$ for $8 \mathrm{~h}$ to avoid water absorption and were then packaged in a desiccant environment. The atomic-resolution image was acquired from an aberration-corrected scanning transmission electron microscopy (AC-STEM, JEOL JEM-ARM 200F) operating at $200 \mathrm{kV}$ in the high-angle annular dark-field (HAADF) mode. Electron energy-loss spectroscopy (EELS, GIF Quantum ER Model 965) was used to probe the valence state information under following parameters: an electron probe of size $<0.13 \mathrm{~nm}$, convergence semi-angle of $29.9 \mathrm{mrad}$, collection semi-angle of $50 \mathrm{mrad}$, energy dispersion 0.25 $\mathrm{eV} \cdot \mathrm{channel}^{-1}$, and instantaneous dwell time of $10 \mathrm{~ms}$. The time-resolved photoluminescence (PL) spectra were recorded on an Edinburgh FLS920 photoluminescence spectrophotometer at room temperature with a picosecond pulsed diode laser (350 nm, pulse width:12 ps).

\section{Photoelectrochemical and photocatalytic measurements}

The light source in all the photoelectrochemical and photocatalytic measurements is the 300 W Xe lamp equipped with an AM 1.5G filter and the calibrated power density is $100 \mathrm{~mW} \cdot \mathrm{cm}^{-2}$ using a power meter (Newport 843-R). Prior to the illumination, the system was purged with $\mathrm{N}_{2}$ for $30 \mathrm{~min}$ to exclude the dissolved $\mathrm{O}_{2}$. 
The photoelectrochemical (PEC) water splitting performance was evaluated in a photoelectrochemical cell using an electrochemical station (CHI 760E, CHI Instrument, Shanghai). The PEC cell was in a three-electrode configuration with the as-prepared sample as the working electrode, platinum foil as the counter electrode, $\mathrm{Ag} / \mathrm{AgCl}\left(3.5 \mathrm{~mol} \cdot \mathrm{L}^{-1} \mathrm{KCl}\right.$ aqueous solution $)$ as the reference electrode, and $0.2 \mathrm{~mol} \cdot \mathrm{L}^{-1} \mathrm{Na}_{2} \mathrm{SO}_{4}$ aqueous solution as the electrolyte. The transient photocurrent density was measured by applying a bias of $1.23 \mathrm{~V}$ vs. RHE under chopped illumination. The applied potential vs. $\mathrm{Ag} / \mathrm{AgCl}$ reference electrode was converted to the reversible hydrogen electrode (RHE) scale according to the Nernst equation:

$$
E_{\mathrm{RHE}}=E_{\mathrm{Ag} / \mathrm{AgCl}}+0.059 \mathrm{~V} \times \mathrm{pH}+E_{\mathrm{Ag} / \mathrm{AgCl}}^{\circ}
$$

where, $E_{\mathrm{Ag} / \mathrm{AgCl}}^{\circ}$ is equal to $0.205 \mathrm{~V}$ at $25^{\circ} \mathrm{C}$.

For a typical fabrication of the working electrode, the sample slurry was mixed by P25 powder, terpineol, and ethyl cellulose at the weight ratio of 7: 2: 1 through grinding. The obtained slurry was dripped onto the FTO substrate, and then was scraped into a uniform film. Subsequently, the slurry coated FTO substrate was annealed at $500{ }^{\circ} \mathrm{C}$ for $30 \mathrm{~min}$ to obtain the prepared working photoelectrode. An effective contact area between the suspension and the FTO is kept to $1 \mathrm{~cm}^{2}$ using the epoxy.

The photocatalytic water splitting performance of samples were evaluated in a closed-cycle gas circulation system connected to a quartz reactor with a top window (Labsolar-III AG, Beijing Perfect light Technology Co., Ltd). In a typical experimental procedure, $0.01 \mathrm{~g}$ of the sample powder was dispersed by ultrasonication for $30 \mathrm{~min}$ in $100 \mathrm{~mL}$ of $0.1 \mathrm{~mol} \cdot \mathrm{L}^{-1} \mathrm{~K}_{2} \mathrm{CO}_{3}$ aqueous solution. The produced $\mathrm{H}_{2}$ was measured by gas chromatography (GC-7880, Beijing Country Spectrum Technology Co., Ltd) with a thermal conductivity detector (TCD), and the carrier gas was high-purity Ar.

\section{Models and computational details}

To understand the electronic structures and the orbital distribution of the hydrogenated $\mathrm{TiO}_{2}$ surface, the DFT and DFT $+\mathrm{U}$ calculation were performed using SIESTA code. ${ }^{1}$ For conventional DFT method, we adopted GGA/PBE functional with the double zeta plus polarization (DZP) orbitals basis to demonstrate the surface modification including the $\mathrm{O}$ vacancy and different type of $\mathrm{H}$ heteroatoms. The (101) surface of anatase $\mathrm{TiO}_{2}$ was modeled by a $1 \times 2$ super cell contained four atomic layers and a ca. $20 \AA$ vacuum layer to avoid potential quantum mechanical overlap. The calculation embraces detailed parameters including a projected atomic orbital energy shift of 
$100 \mathrm{meV}$, an energy cutoff of $300 \mathrm{Ry}$, a maximal displacement tolerance of $1.0 \times 10^{-4} \AA$, and a maximal force threshold of $0.02 \mathrm{eV} \cdot \AA^{-1}$. Because of the strong on-site Coulomb interaction of localized electrons, the PDOS and orbital distribution of all anatase $\mathrm{TiO}_{2}$ models were calculated by DFT $+\mathrm{U}$ method, and a Hubbard $\mathrm{U}$ term of $3.5 \mathrm{eV}$ been applied to Ti $3 \mathrm{~d}$ electrons base on the previous investigation of optimized $\mathrm{U}$ value in oxygen-deficient anatase $\mathrm{TiO}_{2}$ system. ${ }^{2-4}$ 


\section{Figures}

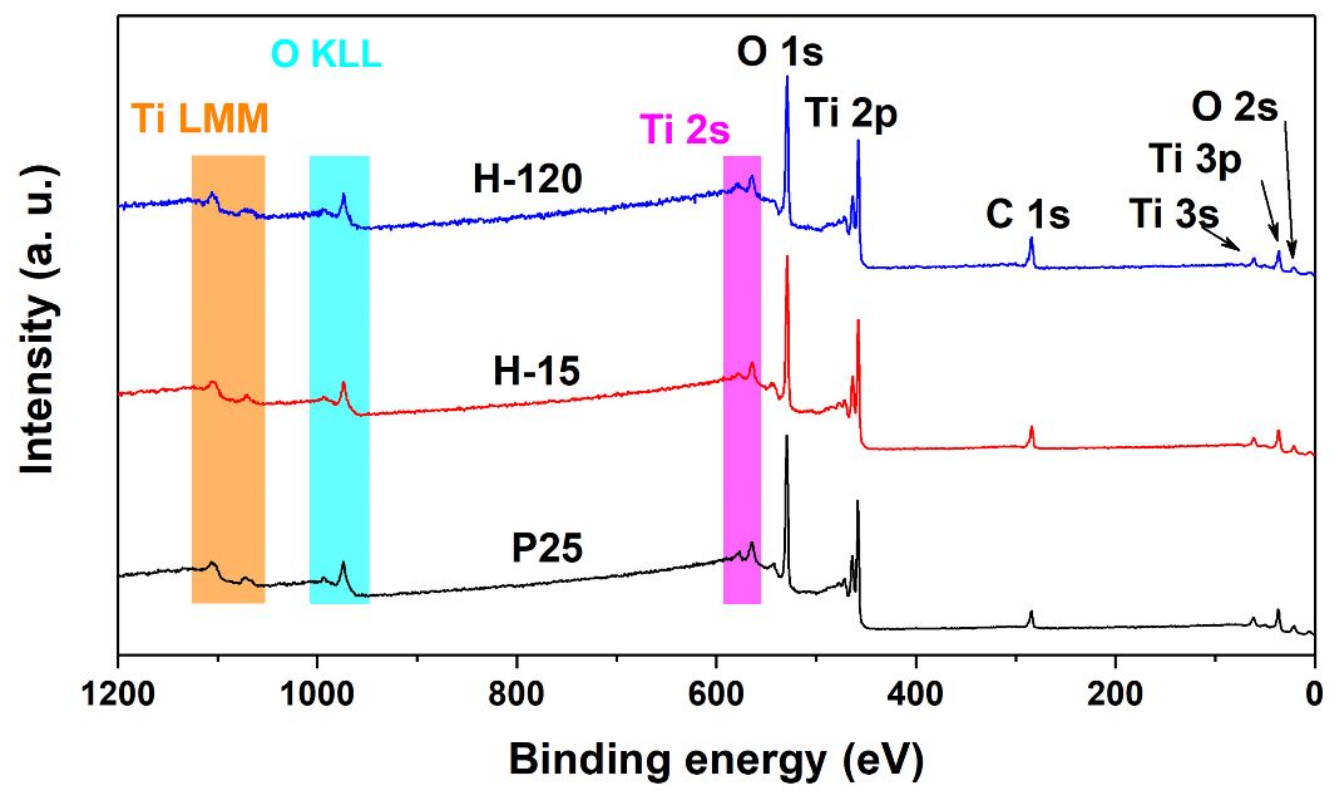

Figure S1. XPS survey spectra of P25, H-15, and H-120. No other elements are observed on the surface of all the P25, H-15, and H-120 samples except Ti and $\mathrm{O}$ elements, where the signals of carbon in all the three samples are from the adventitious carbon. 


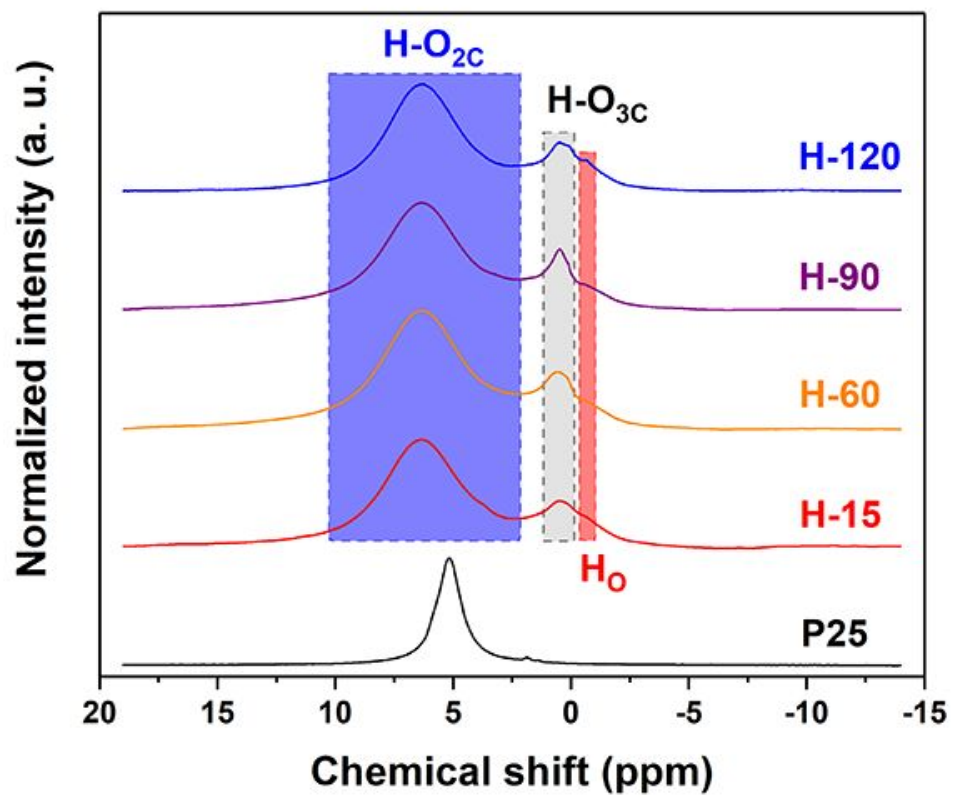

Figure S2. ${ }^{1} \mathrm{H}$ NMR spectra of P25, H-15, H-60, H-90, and H-120 samples. 

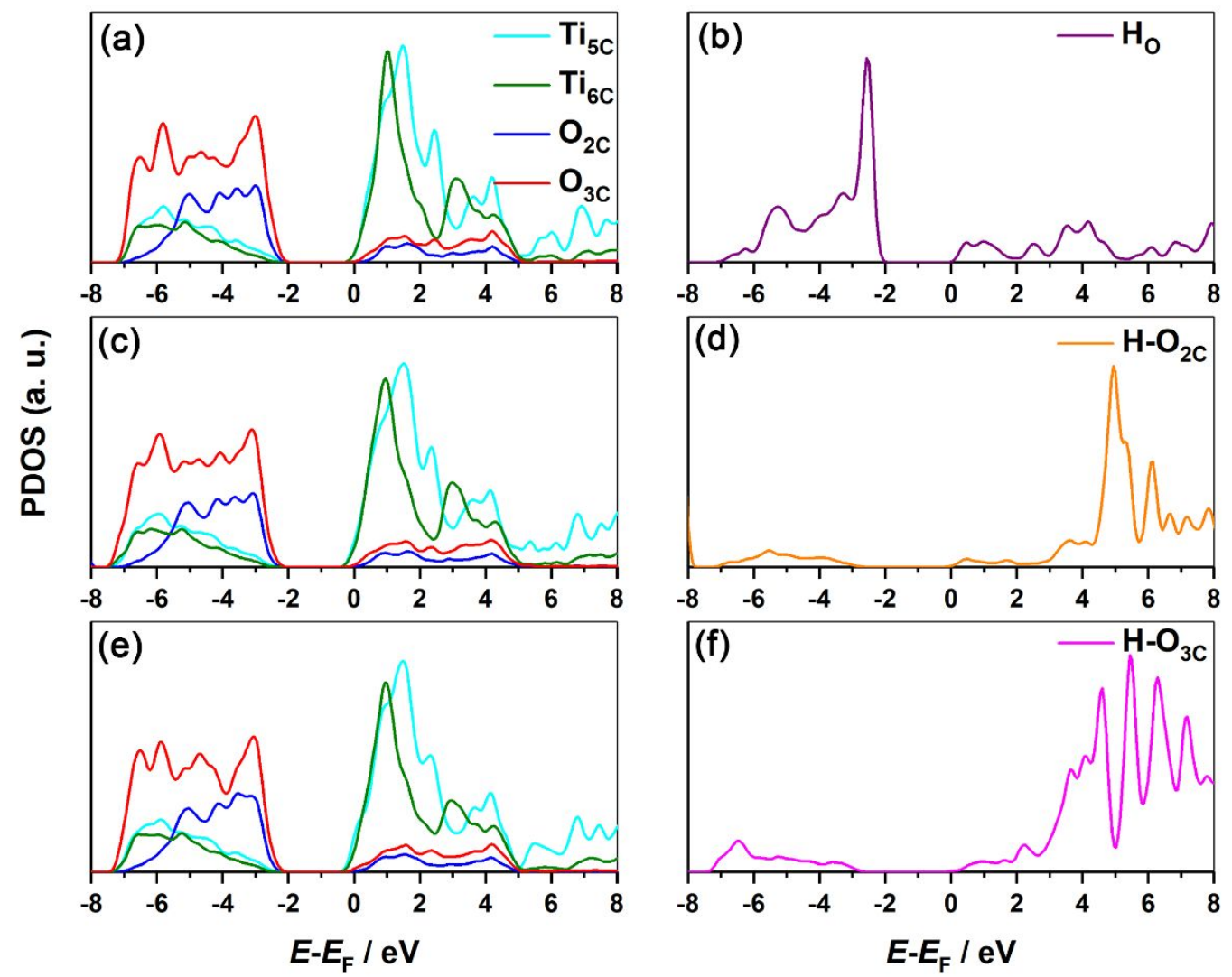

Figure S3. Surface PDOS of relaxed oxygen-deficient (101) surface of anatase $\mathrm{TiO}_{2}$ calculated using conventional DFT method with a) one $\mathrm{H}$ atom located in the $\mathrm{O}$ vacancy $\left(\mathrm{H}_{\mathrm{O}}\right.$ model $), \mathrm{c}$ ) with one $\mathrm{H}$ atom bonded with the $\mathrm{O}_{2 \mathrm{C}}$ atom $\left(\mathrm{H}-\mathrm{O}_{2 \mathrm{C}}\right.$ model $)$, and e) with one $\mathrm{H}$ atom bonded with the $\mathrm{O}_{3 \mathrm{C}}$ atom ( $\mathrm{H}-\mathrm{O}_{3 \mathrm{C}}$ model), respectively. b), d), and f) are the PDOS of the corresponding $\mathrm{H}$ atoms. 

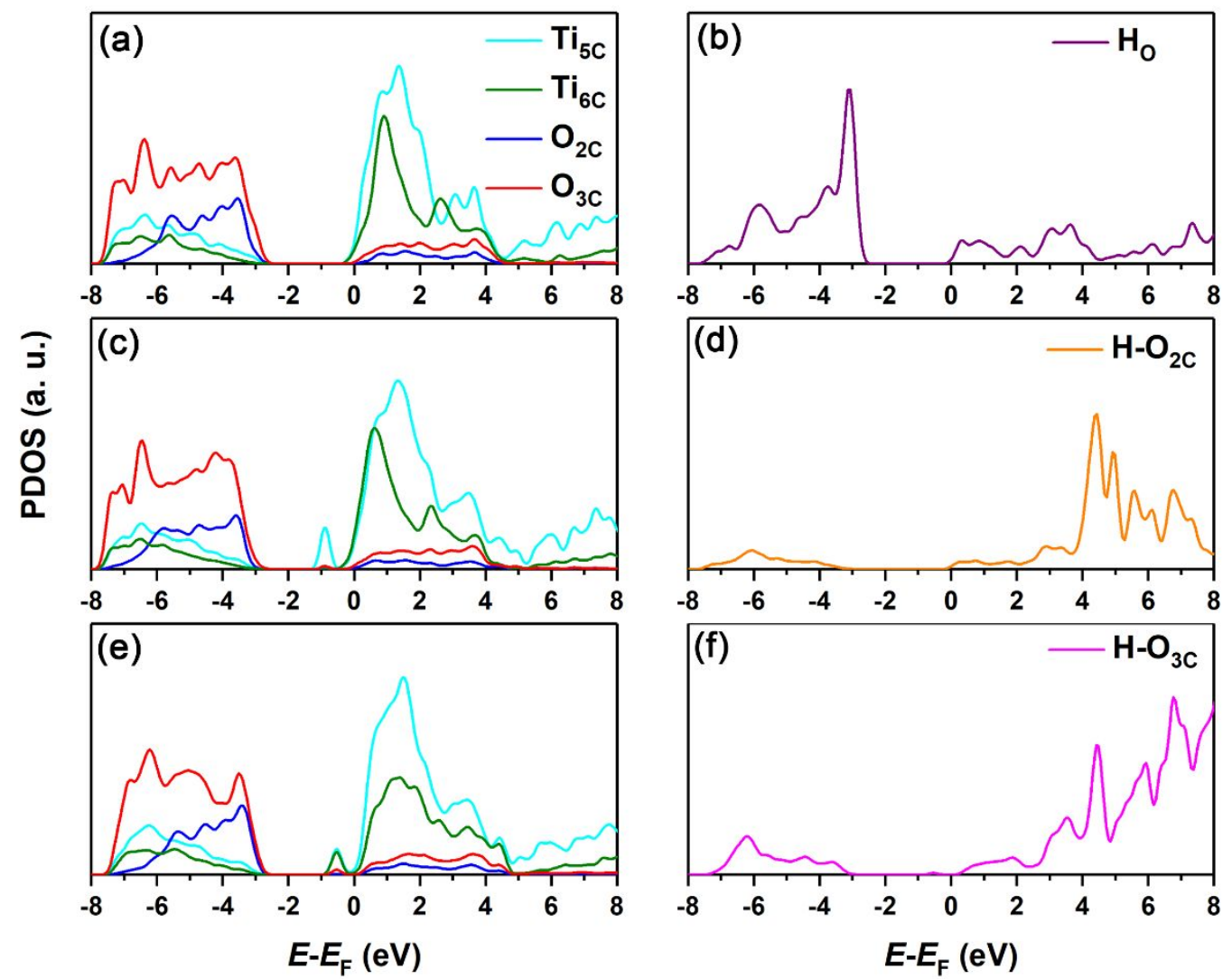

Figure S4. Surface PDOS of relaxed oxygen-deficient (101) surface of anatase $\mathrm{TiO}_{2}$ calculated using DFT $+\mathrm{U}$ method with a) one $\mathrm{H}$ atom located in the $\mathrm{O}$ vacancy $\left(\mathrm{H}_{\mathrm{O}}\right.$ model $)$, c) with one $\mathrm{H}$ atom bonded with the $\mathrm{O}_{2 \mathrm{C}}$ atom $\left(\mathrm{H}-\mathrm{O}_{2 \mathrm{C}}\right.$ model), and e) with one $\mathrm{H}$ atom bonded with the $\mathrm{O}_{3 \mathrm{C}}$ atom $\left(\mathrm{H}-\mathrm{O}_{3 \mathrm{C}}\right.$ model), respectively. $\left.\left.\mathrm{b}\right), \mathrm{d}\right)$, and $\mathrm{f}$ ) are the PDOS of the corresponding $\mathrm{H}$ atoms. 


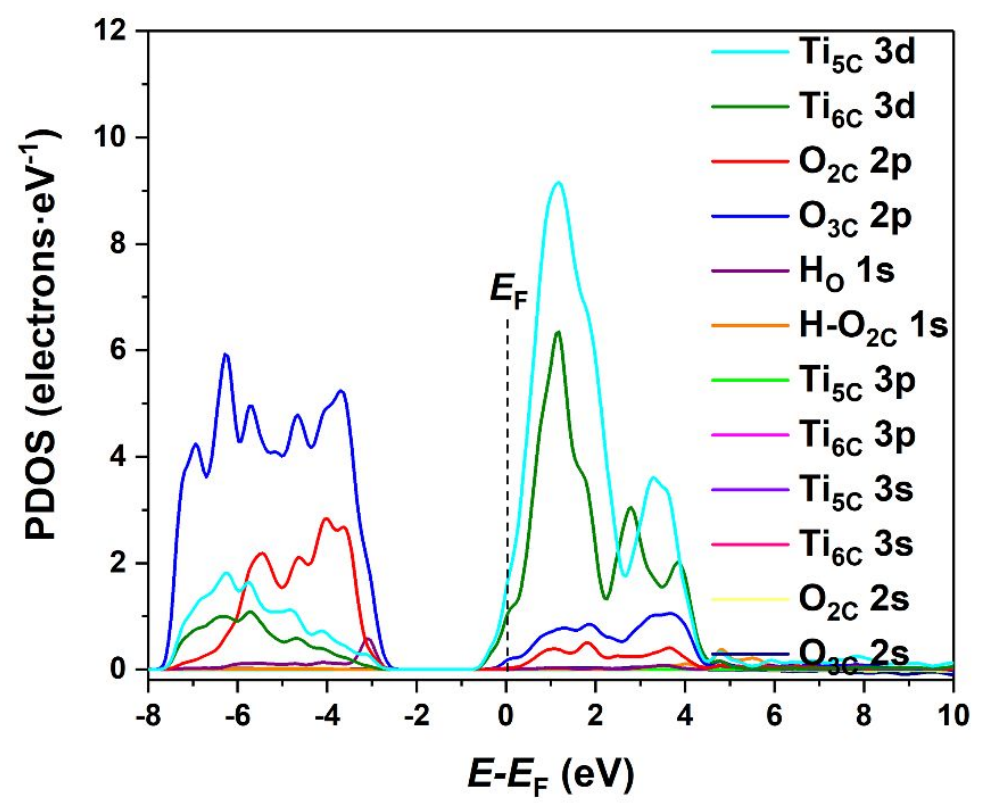

Figure S5. Surface PDOS of relaxed oxygen-deficient (101) surface of anatase $\mathrm{TiO}_{2}$ calculated using DFT $+\mathrm{U}$ method with two $\mathrm{H}$ heteroatoms located in the oxygen vacancy and bonded with the $\mathrm{O}_{2 \mathrm{C}}$ atom, respectively $\left(\mathrm{H}_{\mathrm{O}}+\mathrm{H}-\mathrm{O}_{2 \mathrm{C}}\right.$ model). The conduction band minimum (CBM) of $\mathrm{H}_{\mathrm{O}}+\mathrm{H}-$ $\mathrm{O}_{2 \mathrm{C}}$ model is composed of the dominant $3 \mathrm{~d}$ orbitals of $\mathrm{Ti}_{5 \mathrm{C}}$ and $\mathrm{Ti}_{6 \mathrm{C}}$ atoms, while the valence band minimum (VBM) is composed of the dominant $2 p$ orbitals of $\mathrm{O}_{2 \mathrm{C}}$ and $\mathrm{O}_{3 \mathrm{C}}$ atoms 


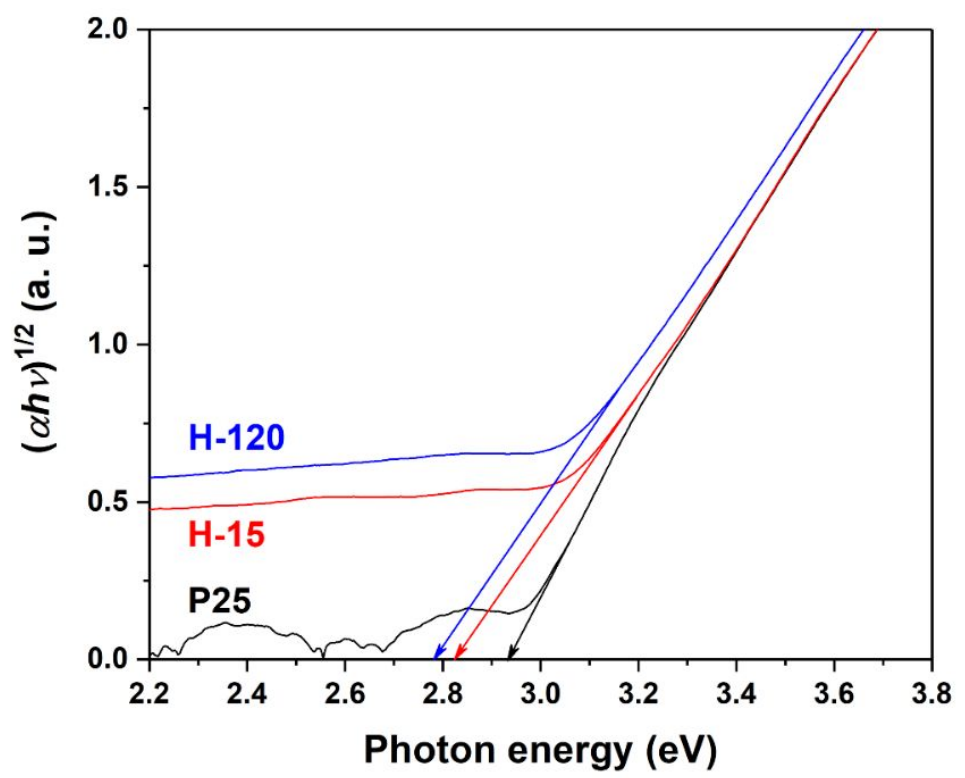

Figure S6. Tauc plots corresponding to the UV-vis spectra in Figure 4a. The optical band gaps of $\mathrm{P} 25, \mathrm{H}-15$, and $\mathrm{H}-120$ samples are determined to be $2.93,2.82$, and $2.78 \mathrm{eV}$, respectively. 


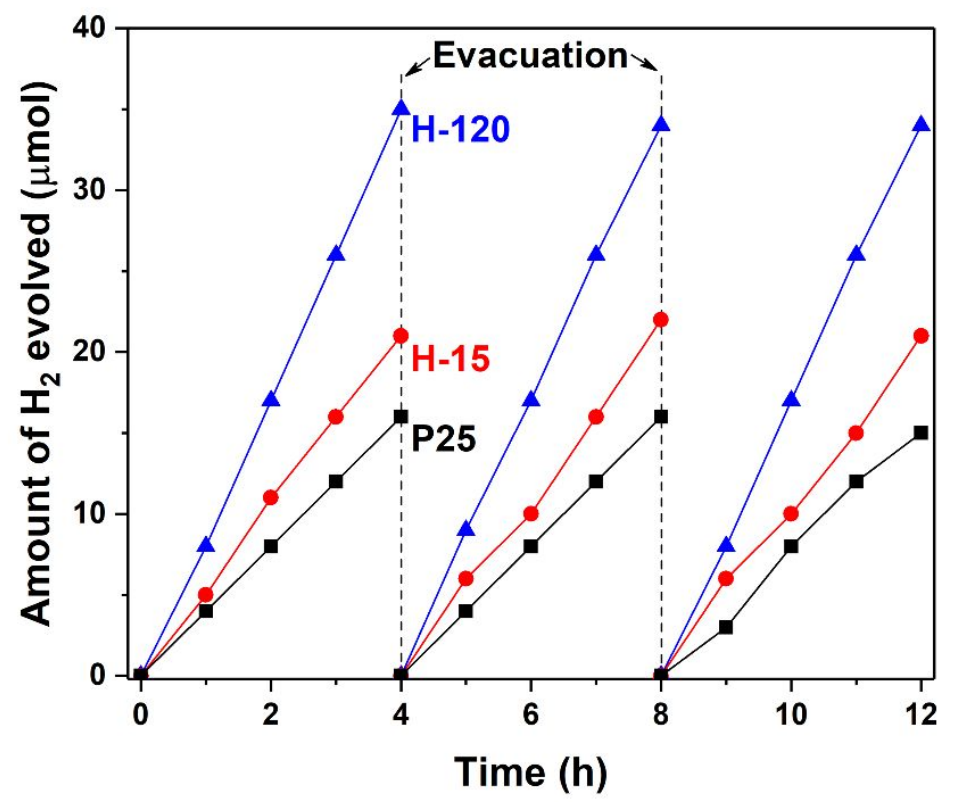

Figure S7. Time courses of photocatalytic hydrogen evolution over P25, H-15, and H-120 samples. The closed-cycle gas circulation system was evacuated every 4 hours without replacing the reaction solution. 

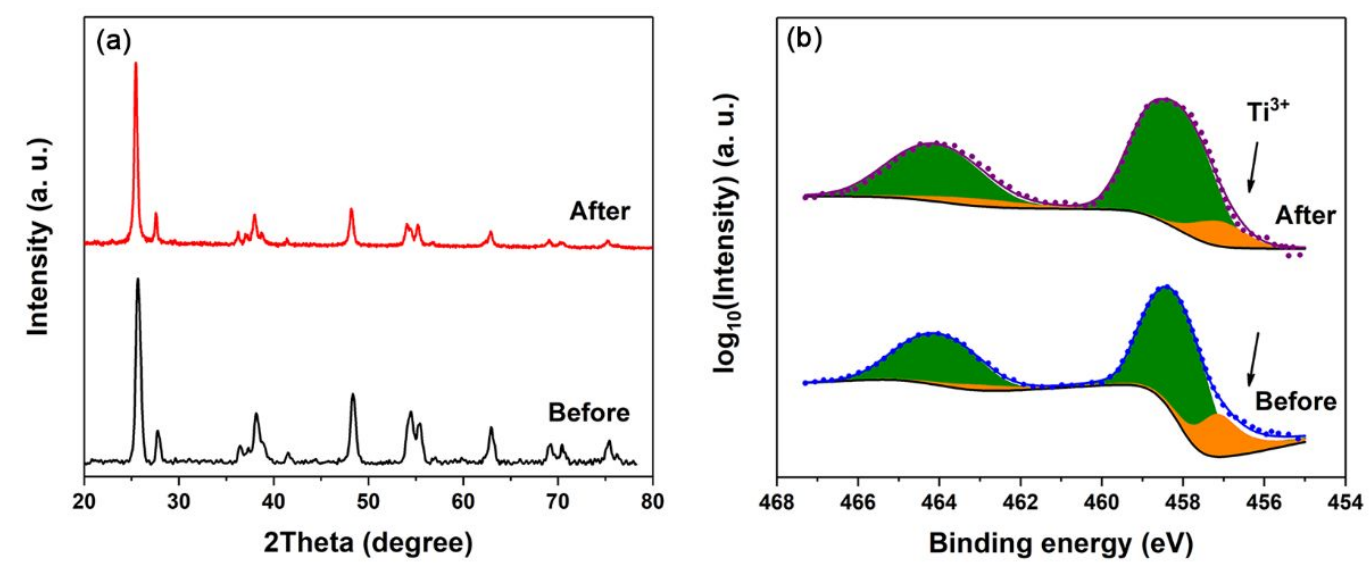

Figure S8. XRD patterns and XPS spectra of H-120 sample before and after photocatalytic hydrogen production reaction. The XRD patterns and XPS spectra of H-120 sample before and after photocatalytic reaction are almost identical, which suggests the hydrogenated $\mathrm{TiO}_{2}$ is stable over the catalytic reaction. 


\section{Section I Synthetic procedure and texture characterization}

As shown in Figure $\mathrm{S}$, the removal of surface $\mathrm{O}$ for $\mathrm{TiO}_{2}$ through anealing in the $\mathrm{H}_{2}$ atmosphere at the standard pressure is a thermodynamically unfavourable process which is contrary to our common sense. Indeed, the oxygen vacancies in hydrogenated black $\mathrm{TiO}_{2}$ are mainly produced through the reduction of bridging-bonded oxygens $\left(\mathrm{O}_{2 \mathrm{C}}\right.$ atoms $)$ by atomic $\mathrm{H} .5,6$ Therefore, this basic understanding provides us a slow kinetics to tune the thickness of the hydrogenated layer.

The commercially available $\mathrm{TiO}_{2}$ (Degussa P25, Sigma-Aldrich) was used as the starting material for hydrogenation. In a typical synthetic procedure of hydrogenation, $0.5 \mathrm{~g}$ of $\mathrm{P} 25$ powder placed in a ceramic crucible boat was annealed in a tube furnace (BTF-1200C, Anhui BEQ Equipment Technology Co., Ltd.) under a diluted hydrogen $\left(5 \% \mathrm{H}_{2} / 95 \% \mathrm{Ar}\right.$ in volume ratio) atmosphere at $500^{\circ} \mathrm{C}$ for $15 \mathrm{~min}$ (denoted as $\mathrm{H}-15$, samples synthesized for different time of hydrogenation are abbreviated analogously). The heating rate was set up for $20^{\circ} \mathrm{C} \mathrm{min}-1$. The asprepared samples were kept natural cooling and then collected for storage. The sketch map of the synthetic procedure is illustrated in Figure S10.

To monitor the possible phase transition during the hydrogenation process, X-ray diffraction (XRD) spectra of P25, H-15 and H-120 samples were measured (Figure S11). The XRD patterns indicate that all the diffraction peaks of hydrogenated samples are identical to the pristine $\mathrm{P} 25$, which means that the bulk structure of all samples are intact and not affected by the hydrogenation. This result is also proved by the Raman spectra (Figure S12) that no detectable shift of the Raman peak assigned hydrogenated samples can be found compared with the Raman spectrum of pristine P25, which indicates the bulk symmetry is not affected by the hydrogenation. However, all the Raman peaks assigned to the hydrogenated samples exhibit a broadening, which is in coincidence with the previous reports of surface disorder induced broadening of the Raman peak. ${ }^{7,8}$ 


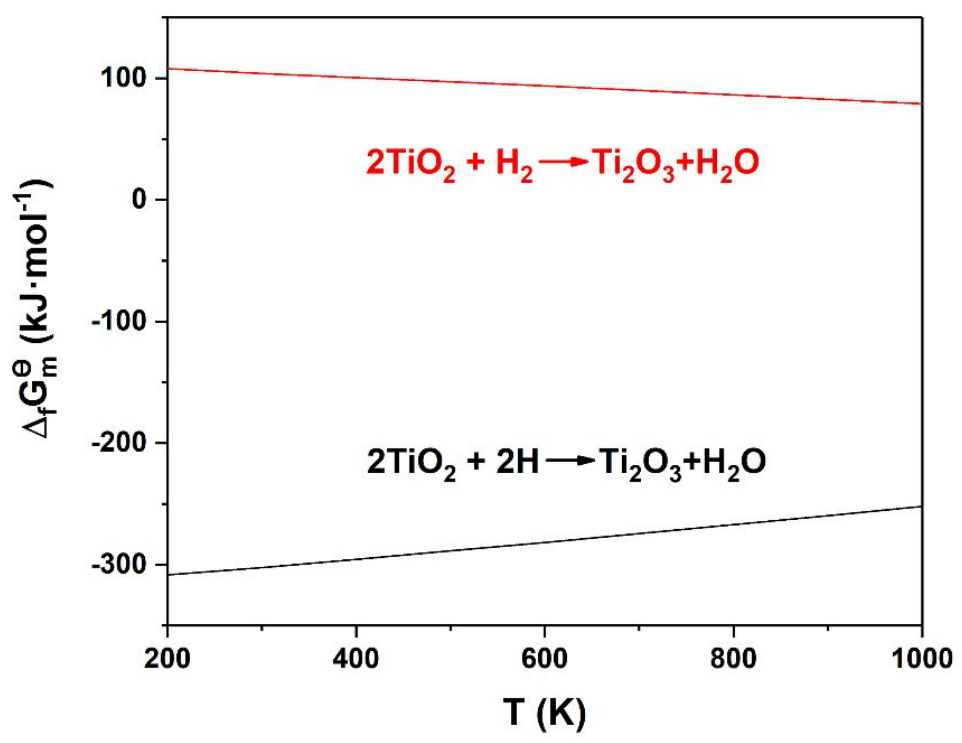

Figure S9. Thermodynamics of reduction of $\mathrm{TiO}_{2}$ by $\mathrm{H}_{2}$ and atomic $\mathrm{H}$ under the standard pressure. The negative value for $\Delta \mathrm{G}$ means a thermodynamically favorable process under the designated temperature. 


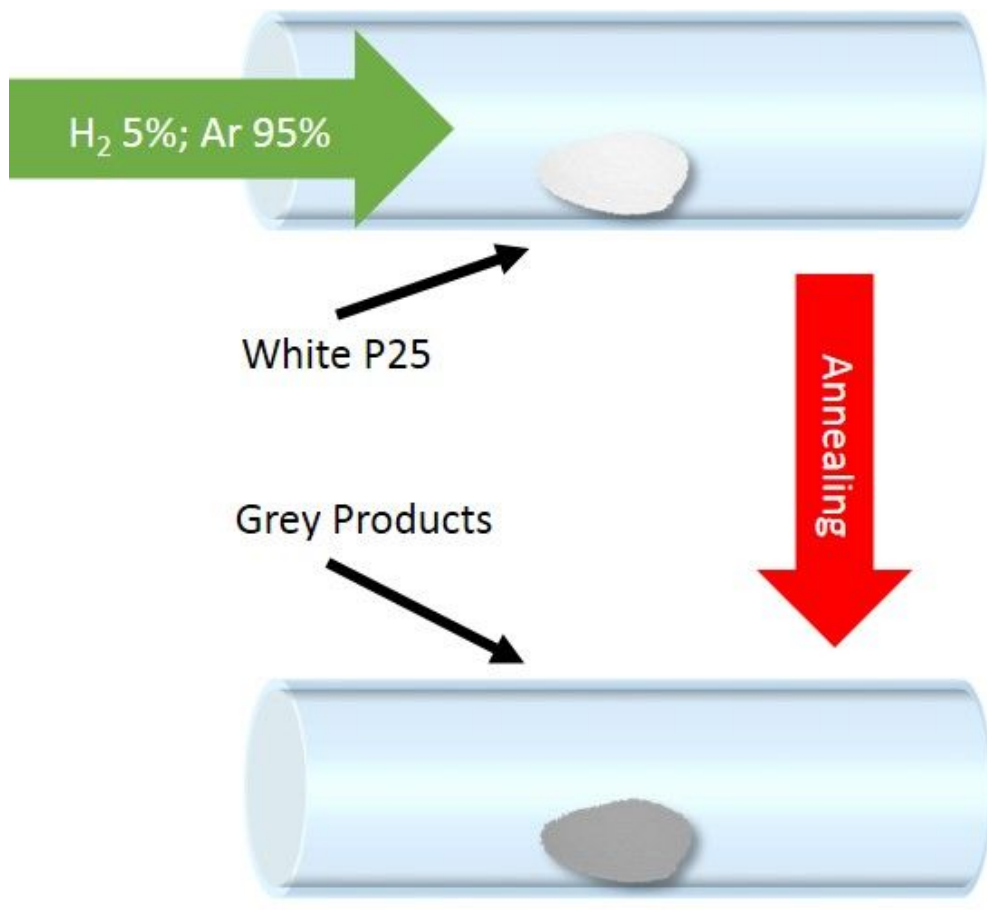

Figure S10. Sketch map of the synthetic procedure for the hydrogenated samples. 


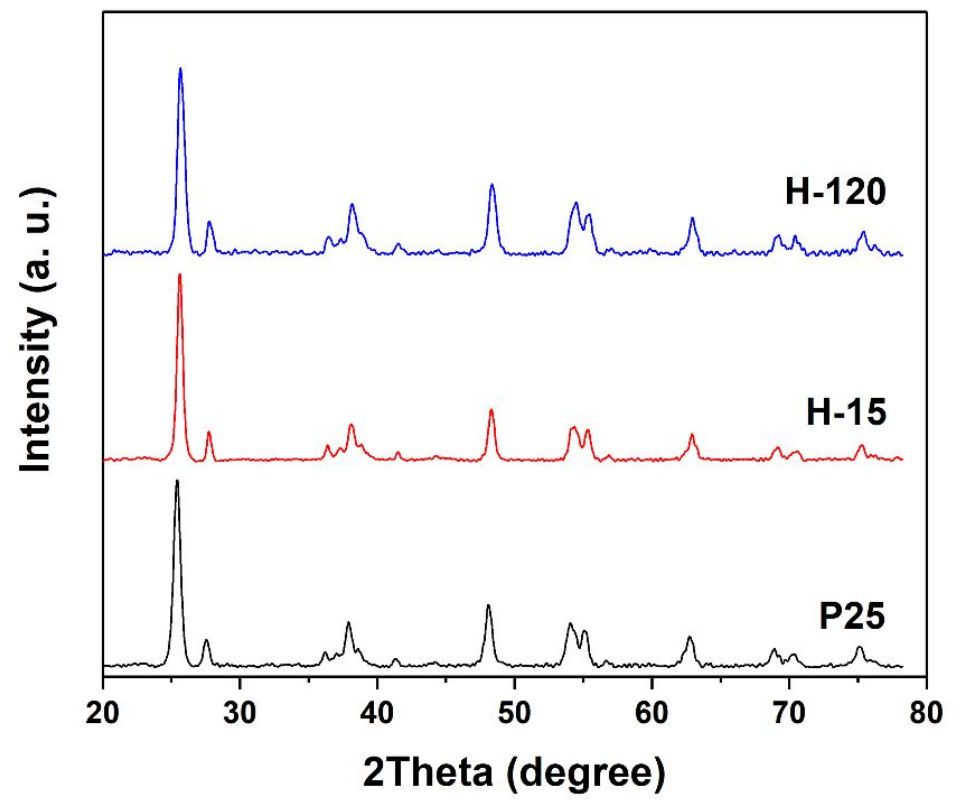

Figure S11. XRD patterns of P25, H-15 and H-120 samples. 


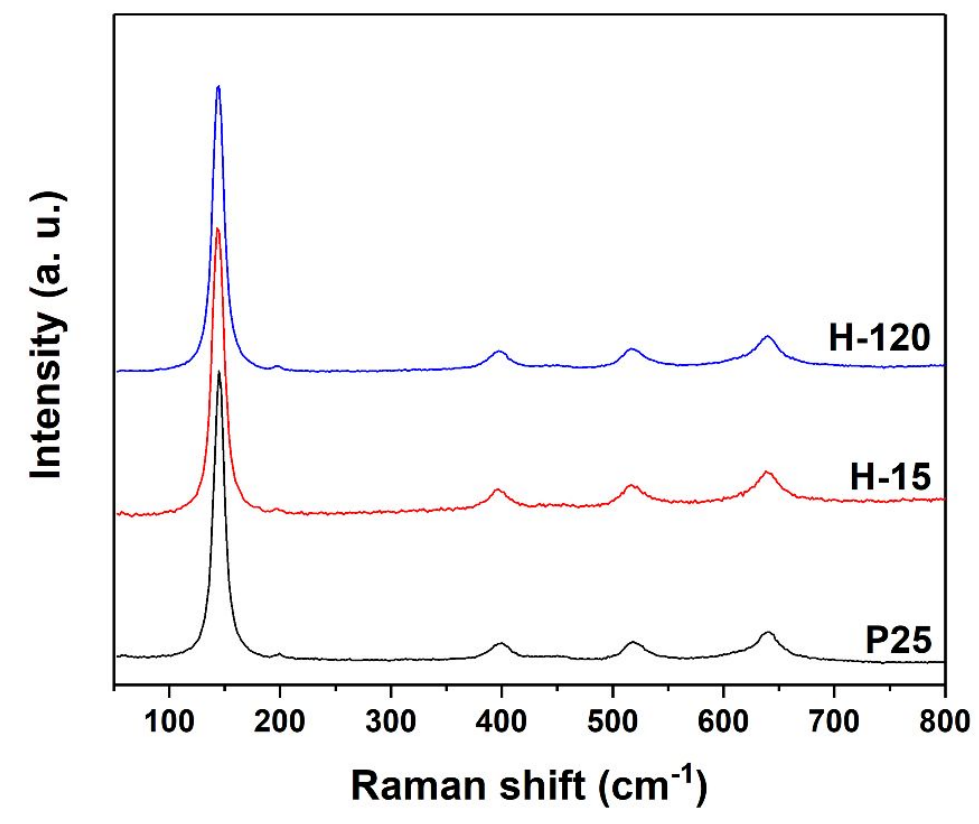

Figure S12. Raman spectra of P25, H-15 and H-120 samples. The Raman characteristic peaks observed at 144, 197, 398, 516, and $640 \mathrm{~cm}^{-1}$ can be assigned to the $E_{g}, E_{g}, B 1_{g}, A 1_{g}+B 1_{g}$, and $E_{g}$ modes of the $\mathrm{TiO}_{2}$ anatase phase, respectively. 


\section{Section II Octahedral distortion}

The degree of the octahedral distortion can be defined as the octahedral distortion parameter $\Delta^{9-11}:$

$$
\Delta=\frac{1}{6} \sum_{n=1-6}\left[\left(d_{n}-d\right) / d\right]^{2},
$$

where $d_{n}$ is the individual length of the Ti-O/H bond, and $d$ is the average length of the Ti-O/H bond in the octahedron associated with Ti atom as the central atom.

It is well known that both anatase and rutile phase of $\mathrm{TiO}_{2}$ are composed of the $\mathrm{TiO}_{6}$ octahedron, while the differences are the distortion degree and the connection manner of the octahedral unit. ${ }^{12}$ The degree of distortion for anatase is higher than rutile, which is one of the most crucial factors for the better photocatalytic redox reactivity of anatase than rutile. ${ }^{13,14}$ By evaluating the degree of octahedral distortion for single $\mathrm{H}_{\mathrm{O}}$ and $\mathrm{H}-\mathrm{O}_{2 \mathrm{C}}$ modified oxygen-deficient (101) surfaces of anatase $\mathrm{TiO}_{2}$ (denoted as $\mathrm{H}_{\mathrm{O}}$ model and $\mathrm{H}-\mathrm{O}_{2 \mathrm{C}}$ model, respectively), the octahedron accommodating $\mathrm{H}$ heteroatom in $\mathrm{H}_{\mathrm{O}}$ model is found to have the minimum degree of distortion thus leading an inhibited charge separation (Figure S13 and Table S1). This can also be endorsed by our previous result that a high symmetry of crystal structure is not a positive factor for photoinduced charge transfer. ${ }^{15}$ 

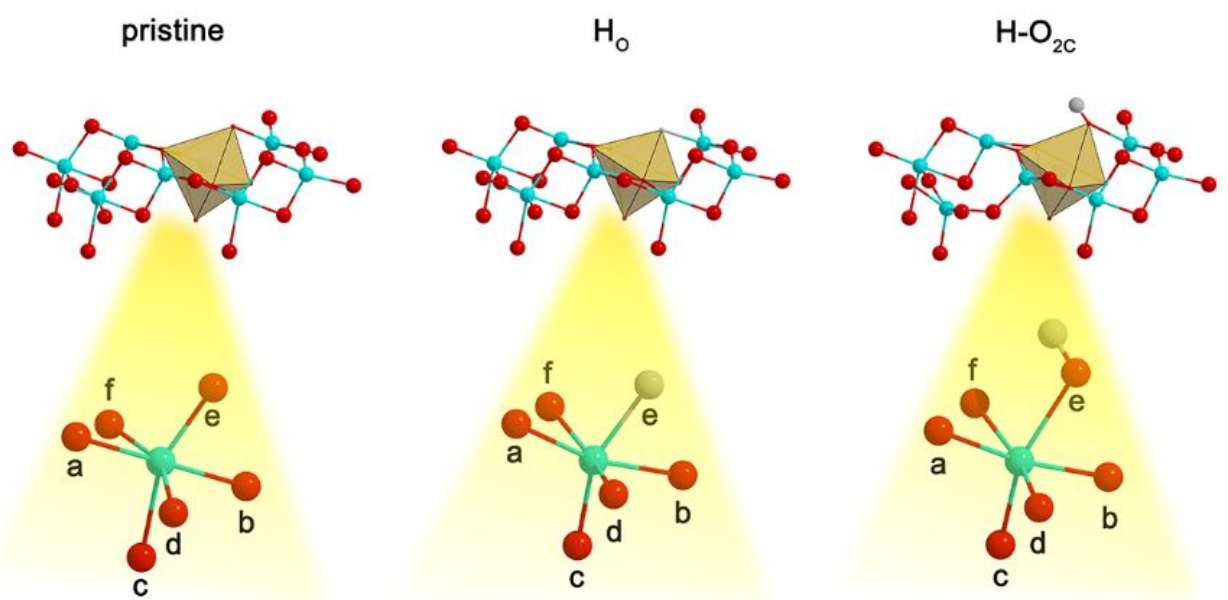

Figure S13. Derivation of the octahedrons for the calculation of the bond length. The octahedrons used for the calculation of the length of Ti-O/H bonds are extracted from the relaxed pristine (101) surface of anatase $\mathrm{TiO}_{2}, \mathrm{H}_{\mathrm{O}}$, and $\mathrm{H}-\mathrm{O}_{2 \mathrm{C}}$ models, respectively. 
Table S1. The length of $\mathrm{Ti}-\mathrm{O} / \mathrm{H}$ bonds and $\Delta$ of the octahedron associated with $\mathrm{Ti}_{6 \mathrm{C}}$ as the central atom.

\begin{tabular}{ccccc}
\hline & & \multicolumn{3}{c}{ Type of relaxed surface } \\
\cline { 3 - 5 } & Position of bond & Pristine (101) & $\mathrm{H}_{\mathrm{O}}$ & $\mathrm{H}-\mathrm{O}_{2 \mathrm{C}}$ \\
& $\mathrm{a}$ & 2.04 & 2.02 & 2.09 \\
& $\mathrm{surface}$ of anatase & 2.04 & 2.01 \\
Bond length & $\mathrm{b}$ & 2.05 & 1.94 & 1.93 \\
$(\AA)$ & $\mathrm{c}$ & 2.18 & 1.91 & 2.18 \\
& $\mathrm{~d}$ & 1.94 & 1.93 & 1.91 \\
& $\mathrm{e}$ & 1.86 & 1.91 & 2.23 \\
\hline
\end{tabular}




\section{Section III Time-resolved photoluminescence spectrum}

The photoluminescence decay curves were fitted following a bi-exponential function:

$$
I(t)=f_{1} e^{\frac{-t}{\tau_{1}}}+f_{2} e^{\frac{-t}{\tau_{2}}} \quad f_{1}+f_{2}=1
$$

where $f_{1}$ and $f_{2}$ are the fractional contributions of the decay components, $\tau_{1}$ and $\tau_{2}$ are the lifetime of the decay components. The average lifetime of the decay components $\left(\tau_{\text {average }}\right)$ is calculated through the following equation:

$$
\tau_{\text {average }}=\frac{f_{1} \tau_{1}^{2}+f_{2} \tau_{2}^{2}}{f_{1} \tau_{1}+f_{2} \tau_{2}}
$$

The overlapped curves indicate similar lifetimes of carriers among the five samples, which is also proved by the fitting results of the time-resolved PL spectra (Figure S14 and Table S2). It is believed that the $\mathrm{H}_{\mathrm{O}}$ heteroatom is the crucial factor to maintain the lifetimes of carriers of different samples at an identical level, because either the single $\mathrm{H}-\mathrm{O}_{2 \mathrm{C}}$ or $\mathrm{H}-\mathrm{O}_{3 \mathrm{C}}$ heteroatom modified (101) surface of oxygen-deficient $\mathrm{TiO}_{2}$ provides band gap states in contrast to the $\mathrm{H}_{\mathrm{O}}$ heteroatom modified surface (Figure S4). Accordingly, the lifetime of carriers in the slightly hydrogenated P25 sample is almost the same even prolonging the time of the hydrogenation process. This further endorses that the enhanced photo(electro)chemical performance of the hydrogenated P25 samples is originated from the improved redox reactivity. 


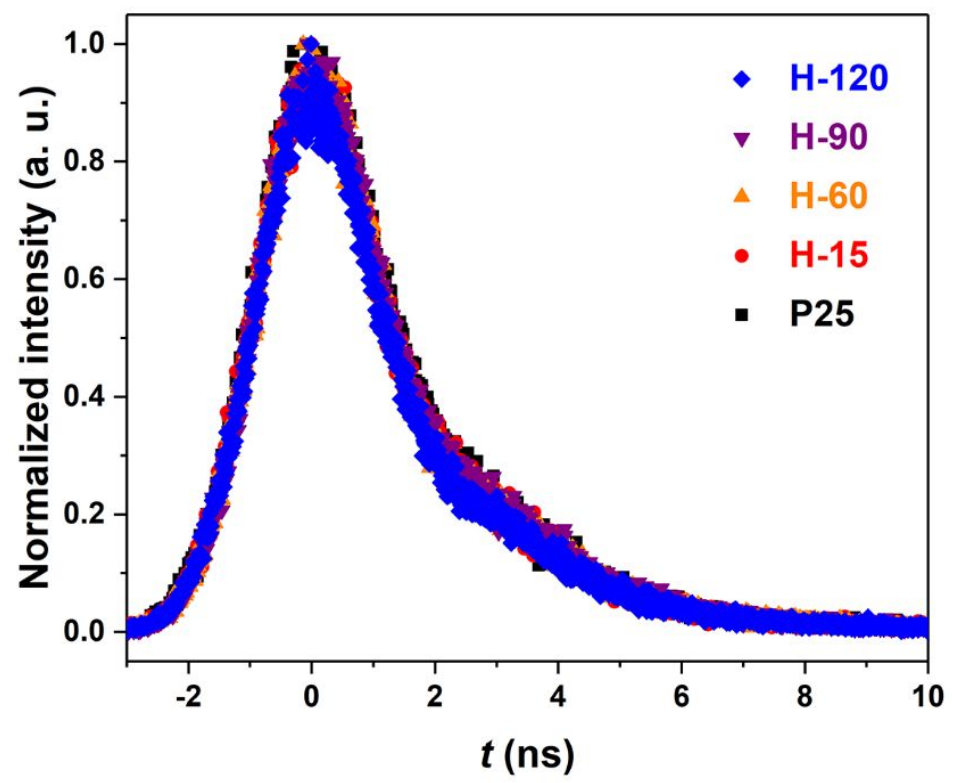

Figure S14. Time-resolved PL spectra of P25, H-15, H-60, H-90, and H-120 samples. 
Table S2. Fitting parameters for time-resolved PL spectra of P25, H-15, H-60, H-90, and H-120 samples.

\begin{tabular}{ccccccc}
\hline & $\tau_{1}(\mathrm{~ns})$ & $f_{1}(\%)$ & $\tau_{2}(\mathrm{~ns})$ & $f_{2}(\%)$ & $\tau_{\text {average }}(\mathrm{ns})$ & $\chi^{2} *$ \\
\hline P25 & 0.352 & 2.413 & 1.899 & 97.587 & 1.89 & 1.07 \\
H-15 & 0.315 & 3.556 & 1.926 & 96.444 & 1.92 & 1.04 \\
H-60 & 0.345 & 4.113 & 1.943 & 95.887 & 1.93 & 1.11 \\
H-90 & 0.310 & 3.521 & 1.955 & 96.479 & 1.94 & 1.20 \\
H-120 & 0.375 & 5.157 & 1.962 & 94.843 & 1.95 & 1.07 \\
\hline
\end{tabular}

$* \chi^{2}$ represents the goodness of the fitting results. Smaller $\chi^{2}$ value indicates a better quality of the fitting results. 


\section{References}

(1) Soler, J. M.; Artacho, E.; Gale, J. D.; García, A.; Junquera, J.; Ordejón, P.; Sánchez-Portal, D. The SIESTA Method for Ab Initio Order-N Materials Simulation. J. Phys. Condens. Matter 2002, 14 (11), 2745-2779.

(2) Setvin, M.; Aschauer, U.; Hulva, J.; Simschitz, T.; Daniel, B.; Schmid, M.; Selloni, A.; Diebold, U. Following the Reduction of Oxygen on $\mathrm{TiO}_{2}$ Anatase (101) Step by Step. J. Am. Chem. Soc. 2016, 138 (30), 9565-9571.

(3) Dette, C.; Pérez-Osorio, M. A.; Kley, C. S.; Punke, P.; Patrick, C. E.; Jacobson, P.; Giustino, F.; Jung, S. J.; Kern, K. TiO 2 Anatase with a Bandgap in the Visible Region. Nano Lett. 2014, 14 (11), 6533-6538.

(4) Selcuk, S.; Selloni, A. Facet-Dependent Trapping and Dynamics of Excess Electrons at Anatase $\mathrm{TiO}_{2}$ Surfaces and Aqueous Interfaces. Nat. Mater. 2016, 15 (10), 1107-1112.

(5) Wang, Z.; Yang, C. Y.; Lin, T. Q.; Yin, H.; Chen, P.; Wan, D. Y.; Xu, F. F.; Huang, F. Q.; Lin, J. H.; Xie, X. M.; Jiang, M. H. H-Doped Black Titania with Very High Solar Absorption and Excellent Photocatalysis Enhanced by Localized Surface Plasmon Resonance. Adv. Funct. Mater. 2013, 23 (43), 5444-5450.

(6) NIST Standard Reference Database 13 https://janaf.nist.gov/?myCountry=H2.

(7) Zhou, W.; Li, W.; Wang, J. Q.; Qu, Y.; Yang, Y.; Xie, Y.; Zhang, K. F.; Wang, L.; Fu, H. G.; Zhao, D. Y. Ordered Mesoporous Black $\mathrm{TiO}_{2}$ as Highly Efficient Hydrogen Evolution Photocatalyst. J. Am. Chem. Soc. 2014, 136 (26), 9280-9283.

(8) Zheng, Z. K.; Huang, B. B.; Lu, J. B.; Wang, Z. Y.; Qin, X. Y.; Zhang, X. Y.; Dai, Y.; Whangbo, M. H. Hydrogenated Titania: Synergy of Surface Modification and Morphology Improvement for Enhanced Photocatalytic Activity. Chem. Commun. 2012, 48 (46), 5733-5735.

(9) Abakumov, A. M.; Erni, R.; Tsirlin, A. A.; Rossell, M. D.; Batuk, D.; Nénert, G.; Tendeloo, G. Van. Frustrated Octahedral Tilting Distortion in the Incommensurately Modulated $\mathrm{Li}_{3 x} \mathrm{Nd}_{2 / 3}$ ${ }_{x} \mathrm{TiO}_{3}$ Perovskites. Chem. Mater. 2013, 25 (13), 2670-2683.

(10) Dwibedi, D.; Araujo, R. B.; Chakraborty, S.; Shanbogh, P. P.; Sundaram, N. G.; Ahuja, R.; Barpanda, P. $\mathrm{Na}_{2.44} \mathrm{Mn}_{1.79}\left(\mathrm{SO}_{4}\right)_{3}$ : A New Member of the Alluaudite Family of Insertion Compounds for Sodium Ion Batteries. J. Mater. Chem. A 2015, 3 (36), 18564-18571.

(11) Hirata, T. Oxygen Position, Octahedral Distortion, and Bond-Valence Parameter from Bond Lengths in $\mathrm{Ti}_{1-x} \mathrm{Sn}_{x} \mathrm{O}_{2}(0 \leq x \leq 1)$. J. Am. Ceram. Soc. 2000, 83 (12), 3205-3207. 
(12) Chen, X. B.; Mao, S. S. Titanium Dioxide Nanomaterials: Synthesis, Properties, Modifications and Applications. Chem. Rev. 2007, 107 (7), 2891-2959.

(13) Scanlon, D. O.; Dunnill, C. W.; Buckeridge, J.; Shevlin, S. A.; Logsdail, A. J.; Woodley, S. M.; Catlow, C. R. A.; Powell, M. J.; Palgrave, R. G.; Parkin, I. P.; Watson, G. W.; Keal, T. W.; Sherwood, P.; Walsh, A.; Sokol, A. A. Band Alignment of Anatase and Rutile $\mathrm{TiO}_{2}$. Nat. Mater. 2013, 12, 798-801.

(14) Setvin, M.; Franchini, C.; Hao, X. F.; Schmid, M.; Janotti, A.; Kaltak, M.; Van De Walle, C. G.; Kresse, G.; Diebold, U. Direct View at Excess Electrons in $\mathrm{TiO}_{2}$ Rutile and Anatase. Phys. Rev. Lett. 2014, 113 (8), 086402.

(15) Yu, Y. G.; Chen, G.; Wang, Q.; Li, Y. X. Hierarchical Architectures of Porous ZnS-Based Microspheres by Assembly of Heterostructure Nanoflakes: Lateral Oriented Attachment Mechanism and Enhanced Photocatalytic Activity. Energy Environ. Sci. 2011, 4 (9), 3652-3660. 